\title{
Economia de Comunhão (EdC): Adorável Mundo Desconhecido! ${ }^{1}$
}

\section{Economy of Communion (EdC): Lovely World Unknown!}

\author{
Ana Carolina Kruta de Araújo Bispo \\ Professora da Universidade Federal da Paraíba - Campus I \\ Doutoranda do Programa de Pós Graduação em Administração - PPGA/UFPB \\ Endereço: Rua, Agente Fiscal Walfredo Bezerra da Silveira, 202 \\ Jardim Cidade Universitária, João Pessoa, PB, Brasil, CEP 58.052-287 \\ e-mail: kruta@terra.com.br \\ Nilda Maria Domingos Mendes \\ Professora da Faculdade JK - Graduação e Pós-Graduação Lato sensu \\ Endereço: SQN 305 Bloco A, Aptº 210 - Asa Norte, Brasília, Brasil, CEP: 70.737-010 \\ e-mail: $\underline{\text { nildamar@terra.com.br }}$ \\ Maria Auxiliadora Diniz de Sá \\ Professora do Mestrado Profissional em Gestão Empresarial da Associação Educacional Boa Viagem. \\ Endereço: Rua Jean Émile Favre, 422, Imbiribeira, Recife, PE, Brasil, CEP: 51.111-020 \\ e-mail: $\underline{\text { msa@fbv.edu.br }}$
}

\section{RESUMO}

Felizmente, algumas empresas já compreendem que a sua performance é função, em grande parte, do reflexo que seu comportamento tem sobre o comportamento de seus funcionários, como é o caso daquelas que aderem ao Projeto Economia de Comunhão (EdC). Apesar de muitos dirigentes empresariais não darem a atenção devida às relações interpessoais, à organização do trabalho e ao estilo de direção, por considerarem os aspectos econômicos e financeiros, talvez como os únicos objetivos realmente importantes, esses são aspectos cruciais ao bem-estar de seu pessoal. Neste sentido, o objetivo geral deste estudo consiste em analisar a qualidade de vida no ambiente de trabalho dos funcionários das empresas que aderem ao projeto EdC, bem como, mais especificamente, àquelas localizadas no Pólo Empresarial Spartaco. Após coleta e análise dos dados, foi possível emitir conclusões nesses termos: a qualidade das relações interpessoais, o modo de organização do trabalho e o estilo de direção adotado permitem inferir que as empresas do Pólo Empresarial Spartaco proporcionam qualidade de vida no trabalho aos seus funcionários. Pode-se ainda afirmar que os valores divulgados pelo Projeto EdC, nos termos estudados são aplicados pelas empresas analisadas, embora ainda se encontrem em adaptação, segundo os próprios dirigentes.

Palavras chave: Economia de Comunhão, Qualidade de Vida no Trabalho.

\section{ABSTRACT}

Fortunately, some companies already understand that your performance is due, in large part, a reflection of their behavior has on the behavior of its employees, such as those that adhere to the Joint Economic Project (JEC). Although many business leaders do not give due attention to interpersonal relationships, work organization and management style, by considering the economic and financial aspects, as perhaps the only really important goals, these are crucial to the well-being of your staff. In this sense, the objective of this study is to analyze the quality of life in the workplace of the employees of the companies that adhere to the JEC and, more specifically, those located in the Spartacus Business Pole. After collecting and analyzing the data, it was possible to issue findings in these terms: the quality of interpersonal relations, mode of work organization and management style adopted allow us to infer that companies Spartacus Business Pole provide quality of life in the workplace for their employees. One could even say that the figures released by the JEC under study are applied by the companies analyzed, although still in adaptation, according to the leaders themselves.

Keywords: Joint Economy. Quality of life in the workplace.

${ }^{1}$ Artigo recebido em 29.05.2013. Avaliado pelos pares em 14.07.2013 (blind review). Reformulado em 22.07.2013. Aceito para publicação em 01.08.2013. Recomendado para publicação por José Ribamar Marques de Carvalho (Editor Científico). Publicado em 15.09.2013. Organização Responsável UACC/CCJS/UFCG. 


\section{INTRODUÇÃO}

Sabendo-se do papel e da importância que o trabalho tem na vida das pessoas, surgiu a preocupação com os aspectos a ele relacionados e que atuam sobre o bemestar e desempenho dos indivíduos. Sendo assim, a qualidade de vida no trabalho (QVT) aparece como um movimento que leva em conta tais dimensões e cujas principais abordagens consideram um conjunto harmonioso e equilibrado de realizações em diferentes níveis, tais como: trabalho, saúde, lazer, desenvolvimento profissional e pessoal, etc.

Infelizmente, apesar das inúmeras vantagens indicadas tanto por acadêmicos quanto por empresários, a melhoria da qualidade de vida no trabalho, ainda não é uma prioridade para muitas organizações, pois muitas delas estão preocupadas apenas com seus objetivos racionais, com o seu lucro, com a diminuição de seus custos e com seus investimentos em bens materiais e financeiros.

Porém, nos cinco continentes, já podem ser encontradas empresas que possuem outros valores, não apenas aqueles materiais e financeiros (aspectos hard), mas também aqueles humanos (aspectos soft). Algumas dessas empresas fazem parte do Projeto Economia de Comunhão (EdC), que é um projeto de âmbito mundial, em que mais de 30 países estão envolvidos, atualmente. Esse projeto teve início no Brasil, em 1991, a partir de um movimento religioso e civil denominado Movimento dos Focolares, o qual se difundiu pelo mundo inteiro, tendo por objetivo contribuir, mediante as mais variadas iniciativas, para um mundo mais justo e solidário.

A sua organização compõe-se de empresas que como tal, procuram se desenvolver competentemente para enfrentar o mercado, ou seja, elas possuem características de outras empresas normalmente conhecidas, como tecnologia de ponta, funcionários bem treinados, capital, enfim, empresas que buscam a geração de lucros, mas que vêem esses lucros como um meio e não simplesmente como um fim, pois o seu objetivo primordial é o "bem-estar social". Com essa mentalidade, buscase alcançar esse objetivo através da divisão dos lucros econômicos em três partes: uma para investir na própria empresa; outra para investir em estruturas que sirvam para a formação de uma nova mentalidade e finalmente, uma terceira para atender às necessidades de famílias que se encontram em situação de pobreza (LUBICH, 1999).

Além disso, aqueles que aderem ao Projeto EdC - empresários, dirigentes, trabalhadores ou outros, comprometem-se em todos os aspectos de suas atividades, por no centro das atenções, as exigências e as aspirações da pessoa humana (LUBICH, 2001, p.16-17). De acordo com Gonçalves e Leitão (2001) as empresas que aderem ao Projeto EdC já representam experiência suficiente para uma avaliação de seu potencial de introduzir mudanças não apenas adaptativas, mas transformadoras, na gestão empresarial, particularmente na gestão de pessoas.

Essas constatações, além de outras, provocaram a busca de respostas ao seguinte problema: quais as percepções das pessoas envolvidas com as atividades das empresas do Projeto EdC quanto a Qualidade de Vida no Trabalho na 
perspectiva das relações interpessoais, da organização do trabalho e do estilo de direção?

Nesse sentido, este trabalho visa analisar a qualidade de vida no ambiente de trabalho dos funcionários das empresas que aderem ao projeto $\mathrm{EdC}$, bem como, mais especificamente, àquelas localizadas no Pólo Empresarial Spartaco, localizado na cidade de Cotia, no estado de São Paulo, a fim de responder ao questionamento acima descrito.

De um lado, este trabalho se justifica, por pretender ampliar os estudos no campo da qualidade de vida no trabalho de ocupantes de cargos não gerenciais. De outro lado, por escolher como campo de pesquisa as empresas de EdC, campo ainda pouco explorado, principalmente no tocante a gestão de pessoas.

Acredita-se ainda que este trabalho seja valioso para a pesquisa científica na área da Gestão dos Recursos Humanos, pois esta ainda é uma área carente em número de pesquisas (CURADO et al., 1995) e ainda, será um instrumento de informação para que profissionais, professores, pesquisadores e estudantes se informem sobre como se encontram as empresas de Economia de Comunhão, em termos de qualidade de vida no trabalho.

\section{REFERENCIAL TEÓRICO}

\subsection{QUALIDADE DE VIDA NO TRABALHO (QVT)}

A certeza de que as inovações tecnológicas por si só promoveriam o bem estar da sociedade, não mais se sustenta. Essa reflexão acaba por sugerir um novo modelo de organização, no qual a necessidade de se ter um patrimônio humano efetivamente disposto a contribuir com os objetivos organizacionais é imprescindível.

Assim, diante de mudanças tecnológicas e estruturais surge a qualidade de vida no trabalho, que apesar das divergências quanto a sua conceituação, os modelos criados a fim de estudá-la, possuem um ponto em comum, que é sua essência humanista.

A respeito disso, Westley (1979 apud SANT'ANNA et al, 2000) afirma que as melhorias voltadas à qualidade de vida no trabalho são provenientes de esforços voltados para humanização e para a busca de soluções de problemas gerados pelas organizações existentes na sociedade industrial.

Seguindo essa mesma linha de raciocínio, Huse e Cummings (1985 apud SANT'ANNA et al., 2000, p.2) entendem a QVT como sendo "uma forma de pensamento envolvendo pessoas, trabalho e organização, destacando-se dois pontos distintos: (a) a preocupação com o bem-estar do trabalhador e com a eficiência organizacional; e (b) a participação dos trabalhadores nas decisões e problemas do trabalho".

Pode-se pensar que essa diversidade de conceito seja devido ao fato de que cada autor revela um elemento diferente sobre esse tema. Para Fernandes (1996), 
todos esses conceitos podem ser reunidos em quatro pontos básicos: (1) a resolução de problemas com o envolvimento de todos os funcionários (participação, sugestões, inovações); (2) a reestruturação da natureza do trabalho (enriquecimento de tarefas, redesenho de cargos, rotação de funções, grupos autônomos ou semi-autônomos); (3) a inovação no sistema de recompensas (remunerações financeiras e não-financeiras); e (4) a melhoria do ambiente organizacional (clima, cultura, ambiente físico, aspectos ergonômicos e assistenciais).

Para Aguiar (2000) é o lazer que deve ser visto como importante indicador de qualidade de vida, pois o mesmo ajuda no desenvolvimento das faculdades cognitivas da intuição, da criatividade, da sociabilidade, e da capacidade de simbolizar e de interagir, importantes nas novas formas de organização do trabalho.

Outros preferem associar a QVT aos aspectos ligados à saúde. É o caso de Silva (2000, p.02), por exemplo, quando afirma que é necessário compensar o colaborador, mostrando-lhe a importância de seu trabalho, sob pena de haver aumento do estresse e até mesmo problema com drogas. Afirma ainda, que uma alimentação saudável, exercícios físicos, ausência de hábitos nocivos, dentre outros, são aspectos da qualidade de vida. Já para Marchi (2000), a introdução dos programas de QVT nas organizações foi influenciada pelos elevados gastos com saúde.

Voltado para as condições de trabalho Hackman e Lawler (1971 apud SANT'ANNA et al., 2000), afirmam que qualidade de vida no trabalho é um instrumento que visa tornar os cargos mais produtivos e satisfatórios e, através do enriquecimento dos mesmos, aumentar os níveis de motivação e bem-estar dos trabalhadores.

Para Walton (1973 apud MACHADO, 1996), um dos mais conhecidos estudiosos desse tema o conceito de qualidade de vida no trabalho (...) envolve o atendimento às necessidades e aspirações do indivíduo, através da reestruturação do cargo e de novas formas de organizar o trabalho, aliadas a formação de equipes de trabalho com maior poder de autonomia e melhoria do ambiente organizacional.

Ainda segundo Walton (1973 apud SILVA; ANTUNES, 2002), a meta de um programa de qualidade de vida do trabalhador é gerar uma organização mais humanizada, em que o trabalho envolva, simultaneamente, relativo grau de responsabilidade e de autonomia em nível do cargo, recebimento de recursos de "feedback" sobre o desempenho, com tarefas adequadas, variedade, enriquecimento do trabalho e com ênfase no desenvolvimento pessoal do indivíduo.

Machado (1996, p.47), afirma ainda, que a "qualidade de vida no trabalho envolve administração participativa na qual o trabalhador passa a contribuir com seus conhecimentos, suas experiências, a fim de tornar os cargos mais produtivos e satisfatórios".

Outros autores passam a ver a qualidade de vida no trabalho de maneira mais abrangente, percebendo que a mesma não está relacionada apenas aos aspectos 
tangíveis, mas àqueles intangíveis também, como corrobora Bom Sucesso (1997, p 3637):

“[...] qualidade de vida no trabalho não decorre apenas de salário acima do mercado e de invejável plano de benefícios. Resulta do tratamento humano, da gentileza, da leveza nas relações, da possibilidade de expressão de pontos de vista divergentes, do relacionamento sincero, do respeito aos ausentes e do orgulho pelo que se faz".

Já para Guest (1979 apud VIEIRA, 1996, p.358) qualidade de vida no trabalho consiste em "um processo pelo qual uma organização tenta revelar o potencial criativo de seu pessoal, envolvendo-os em decisões que afetam suas vidas no trabalho".

Diante das diversas definições a respeito da QVT, este estudo vai considerar aquelas que ressaltem as relações interpessoais, no tocante ao trabalho em grupo, a camaradagem, a confiança e a solidariedade no ambiente de trabalho; a organização do próprio trabalho, em termos de constituição das tarefas, autonomia e participação dos membros nos processos, ações e tomadas de decisões e, ainda; o estilo de direção, pois se acredita, que aspectos como proximidade entre superiores e subordinados, controle indireto e comunicação no local de trabalho, sejam importantes para a qualidade de vida dos trabalhadores.

\subsubsection{O Relacionamento Interpessoal}

Atualmente, se reconhece que as relações interpessoais não somente têm efeitos positivos na área social, mas também na área econômica. Isso é mesmo proclamado pela própria teoria econômica, a qual busca adaptar sua linguagem introduzindo novos conceitos, tal como, o capital social. A partir dessa constatação, pode-se afirmar que importantes condições para o desenvolvimento econômico e, em particular, para o florescimento das organizações são encontradas nos elementos do capital social, como por exemplo, o respeito pelas regras de convivência, a camaradagem e a solidariedade, tanto entre os membros de uma determinada organização, quanto entre estes e a sociedade (GUI, 2002).

Para Vergara e Branco (2001, p. 20), são ingredientes importantes das organizações de sucesso, ou melhor, das "empresas humanizadas": o trabalho em grupo, a confiança, a camaradagem e a solidariedade.

O trabalho em grupo é visto não somente como uma possibilidade ou um meio de integração entre as pessoas; como um dos princípios que incentivam o desenvolvimento do sentimento de vinculação e de cooperação (MORIN, 2001), mas também como um meio para a satisfação de algumas necessidades interpessoais dos seres humanos. Para Schutz (1958), essas necessidades podem ser satisfeitas normalmente por um equilíbrio de relações em três zonas: aquela da inclusão referente à necessidade de se sentir considerado e importante pelos outros membros 
do grupo; a de controle - relativo ao respeito pela competência e responsabilidade entre as pessoas e, por fim, a de afeição - que são sentimentos de amor mutuamente.

Sá e Lemoine (1998) enfatizam que a integração entre os membros de uma organização pode ser facilitada pela ausência de formalismo, pois desde que o clima sugira simplicidade, as relações entre as pessoas se tornarão mais fáceis e os sentimentos de solidariedade, de camaradagem e de confiança entre eles tenderão a aumentar. De um lado, para os empregados estes são sentimentos de grande valor; de outro, para as empresas considerá-los é fundamental para o seu desenvolvimento e competitividade. Constatações como essas é que buscamos explicar através deste trabalho.

Sabe-se que a confiança implica uma atitude segura em relação ao outro; que pode se basear em uma evidência mesclada de experiência e percepções mais subjetivas, tais como: afeto, admiração, respeito ou reverência. Enfim, a confiança está relacionada à dependência e à crença. Deste modo, um ambiente de confiança é aquele no qual as pessoas entendem que o esforço ou até mesmo o sacrifício que fizerem em prol da organização ou do grupo será de imediato, ou mais tarde, reconhecido. Por parte da organização, ela reconhece que não é preciso supervisão cerrada aos funcionários, pois estes são responsáveis e, portanto não irão prejudicar a organização (GOMES 1999).

Felizmente a solidariedade é uma característica marcante da cultura brasileira, como constatam Sá e Lemoine (1999), ao afirmarem que a maior parte dos membros de organizações brasileiras compartilha de sentimentos comuns, como solidariedade e ajuda mútua nos momentos difíceis, necessidade de se sentir em casa no trabalho, hospitalidade e harmonia. Entre outros fatores, em organizações brasileiras, aspectos do relacionamento interpessoal, como a solidariedade é um dos fatores responsáveis pelo comprometimento das pessoas em organizações.

Segundo Ferrucci (2002), um ambiente de relações solidárias é aquele no qual cada um pode agir sem temores nem cálculos de conveniência pessoal e, portanto, possa exprimir-se até o mais alto nível do trabalho humano: o trabalho criativo. A solidariedade, desta forma, pressupõe que o relacionamento entre os membros de uma organização, dentre outras características, é também baseado na camaradagem. Aspecto abordado a seguir.

Sobre a camaradagem, Gomes (1999) revela que ela pode ser identificada em um ambiente de trabalho onde geralmente as pessoas se encontram, são amigas, casamse e viram compadres e comadres. As pessoas se ajudam nas tarefas, evitam fazer politicagem como forma de obter resultados e não tramam contra seus colegas. Todos se sentem como parte de uma grande família ou de uma comunidade especial. Eles demonstram claramente que gostam de estar uns com os outros e até se encontram fora do trabalho. O clima é de amizade e o ambiente é descontraído e informal.

O desenvolvimento dos sentimentos de solidariedade, camaradagem e confiança nas empresas vai depender, de um lado, dos funcionários e de sua 
competência interrelacional; de outro, da organização e de sua capacidade em propor um clima de simplicidade, segurança e estímulo ao igualitarismo, através do encorajamento de uma relação global entre a direção e os empregados.

\subsubsection{Organização do Trabalho}

O modo de organização do trabalho tem mudado muito ao longo dos anos. A princípio, no âmbito agrícola, ele era executado por índios e depois por negros africanos, de maneira coletiva e com bastante autonomia e participação de todos os envolvidos. A atividade artesanal persistiu por muitos anos, até que no início do século $X X$, as técnicas de produção em série do sistema taylorista-fordista se encarregaram de sufocar essas referências culturais, transmitidas de geração em geração. O trabalho tornou-se, então, simplificado e as tarefas, por sua vez, tornaramse elementares ou parceladas, repetitivas e monótonas e os indivíduos cada vez mais sem autonomia.

Dessa maneira, nota-se que não eram oferecidas às pessoas, boas condições de trabalho, ao menos aquelas definidas pelos teóricos em qualidade de vida, porém, mais recentemente novas formas organizacionais foram surgindo, tanto no ocidente (principalmente na Europa) quanto nos países asiáticos.

Grandjean (1998) afirma que vários levantamentos realizados mostraram que uma parte importante dos trabalhadores pesquisados acha sua tarefa repetitiva, mas, curiosamente a acham interessante e que frequentemente só uma metade acha seu trabalho monótono. Dessa forma, Grandjean, (1998, p.153) ainda afirma que: "nem a prática empresarial nem pesquisas científicas conseguiram ainda, até hoje, encontrar um efeito uniforme do trabalho monótono e repetitivo sobre as pessoas, em relação à satisfação com o trabalho".

Neste mesmo sentido pode-se citar os trabalhos de Sá (1997) e Sá e Lemoine (1999), onde situações precárias de trabalho, tais como: tarefas repetitivas e com poucas chances de autonomia não foram consideradas enfadonhas pelos seus executores, bem como ambientes quentes e barulhentos, com as mínimas condições de conforto não chegaram a prejudicar o comprometimento de operários em seus trabalhos.

No modo de organização do trabalho, a qualidade de vida pode ser ainda estimulada, através da participação dos indivíduos nos processos de decisão. Permitir a participação dos funcionários nos processos de decisões organizacionais, mesmo apenas àquelas concernentes ao seu trabalho, não é uma tarefa fácil, pois "a participação é um exercício infinitamente mais complexo na prática do que aparenta, da mesma maneira que o exercício da democracia é tão mais trabalhoso do que a ditadura" (SEMLER, 1988, p.74).

Além dos elementos citados, pode-se destacar a importância da autonomia dispensada aos envolvidos para resolver os problemas concernentes ao seu trabalho como um dos elementos essenciais para satisfação dos funcionários. Para Garcia 
(1999, p.112) "a autonomia depende da boa comunicação e de um alto grau de cumplicidade entre chefes e subordinados".

\subsubsection{Estilo de Direção}

Com relação ao Estilo de Direção, a QVT pode se apresentar de diferentes formas podendo variar desde um estilo mais democrático até outro mais autoritário. No primeiro caso acentua-se o interesse pelas relações sociais e políticas de trabalho com um maior grau de proximidade entre superiores e subordinados, decisões em equipe, interdependência e liberdade e comunicação aberta. No segundo, enfatiza-se a tarefa, o uso excessivo do poder na gestão e o comando autoritário (PICCININI; OLIVEIRA, 2002).

Para Dejours (1992, p.75), as relações exercidas se traduzem em "todos os laços humanos criados pela organização do trabalho: relação com a hierarquia, com as chefias, com a supervisão, com outros trabalhadores (...)", são de fundamental importância para determinar o estilo de direção das organizações. Desta forma, existem alguns aspectos que na visão deste trabalho, são de fundamental importância para o exercício da liderança nas organizações.

O controle é um deles. Sabe-se que no sistema taylorista-fordista o controle sobre os trabalhadores se dá de forma acirrada. Contrariamente, "no sistema de células de produção ou grupos semiautônomos, onde as equipes são multifuncionais, a forma de controle leva em consideração à própria qualificação dos trabalhadores" (OLIVARES, 1994, p.37). Essa é mais uma exigência desses novos tempos, quando as organizações precisam ser mais flexíveis a fim de estimular a criatividade dos indivíduos.

Para Semler (1988 apud CAIXETA, 2001, p.40-50), o credo vigente na sua empresa, a Semco, é que "a liberdade fortalece a responsabilidade, e não o contrário; ou seja, a chave do sucesso reside na eliminação de controles que costumam aprisionar a capacidade de iniciativa dos funcionários, além de deixá-los desmotivados".

A nova exigência para as organizações que querem continuar no mercado, é que as mesmas se tornem organizações holísticas, se preocupem menos com o controle dos processos e encoraje mais o relacionamento entre líderes e liderados, entre os colegas, entre as unidades das organizações. Mais: ela deve ser consciente do contexto maior: o humano, corporativo, social e ecológico- e deve aumentar suas relações com ele (COHEN, 1999).

A comunicação é outro fator determinante do estilo de direção. Ela deve se dá de forma aberta entre os subordinados e os superiores, devendo esses últimos ao menos ouvir as ideias dos primeiros. Nas organizações a comunicação deve permear todos os níveis e processos, assegurando que as metas organizacionais, os objetivos do negócio e principalmente, o papel de cada colaborador seja entendido, para que desse modo o sucesso seja alcançado. A comunicação tem sido ainda utilizada como 
instrumento estratégico de gestão. Segundo Polignano (1995, p.31), “a qualidade de vida das organizações depende fundamentalmente da qualidade da comunicação".

A proximidade é outro aspecto importante no estilo de direção. Entre dirigentes e dirigidos ela é de grande valia para o sistema de gestão. O contato direto entre esses atores e, ainda mais, quando os primeiros se mostram interessados pelos problemas pessoais desses últimos, isso gera um clima de confiança e contribui enormemente para aumentar a qualidade de vida dos membros envolvidos.

Segundo Friedman et al (2001) reconhecer e dar suporte a pessoa beneficia não apenas o indivíduo, mas também a empresa, ele ainda afirma que todos devem ser tratados de maneira "especial" e as prioridades pessoais devem ser levadas em consideração.

\subsection{ECONOMIA DE COMUNHÃO}

O Projeto Economia de Comunhão é concebido como “um modelo empresarial, orientado por princípios cristãos, pelo qual se efetiva um modo peculiar de lidar com os bens, com o lucro e com as relações humanas" (THIEMER, 1999, p. 101). É uma experiência específica de economia solidária e tem suas bases fundadas no Movimento dos Focolares - movimento religioso que surgiu na comunidade de Trento, na Itália, há 50 anos, durante a Segunda Guerra Mundial, onde Chiara Lubich, líder do movimento e suas primeiras companheiras adotaram como ideal a unidade de um mundo unido.

Esse Projeto teve início no Brasil em 1991, quando Chiara Lubich, em uma visita a São Paulo, ficou impressionada ao ver grande extensão de favelas ao lado de uma das maiores concentrações de arranha-céus do mundo. Sentiu então a necessidade de prover para os habitantes dessas favelas, as necessidades básicas, tais como: alimento, teto, cuidados médicos, e por que não, trabalho também.

A partir daí, apresentou o Projeto Economia de Comunhão, inicialmente chamado Projeto Brasil.

\footnotetext{
“Nesse Projeto, já difundido não somente nos Estados Unidos, mas também na América Latina, Europa e em outras partes do mundo, as empresas participantes se propõem a distribuir seus lucros em três partes: uma para reinvestir na própria empresa, outra para ajudar os que sofrem necessidades e, finalmente outra, para o desenvolvimento do próprio projeto" (LUBICH, 2002, p. 15).
}

Com essa mentalidade, existem atualmente no Brasil, 82 dessas empresas e no mundo elas são aproximadamente 700 .

Segundo Lubich (1999, p. 17), aqueles que aderem a esse Projeto - empresários, dirigentes, trabalhadores ou outras figuras empresariais - se comprometem em pôr no centro das atenções, as aspirações da pessoa humana e os requisitos do bem comum. Em especial elas devem buscar: 
- "instaurar relacionamentos leais e respeitosos com clientes, fornecedores, poder público e até mesmo concorrentes;

- valorizar os empregados, informando-os e envolvendo-os na gestão organizacional;

- manter uma linha de conduta da empresa inspirada na 'cultura da ética';

- reservar grande atenção ao ambiente de trabalho e à natureza, mesmo que arcando com investimentos de alto custo;

- cooperar com outras realidades empresarias e sociais, não somente locais, mas também internacionais, com as quais se sentem solidárias".

Finalmente, a Economia de Comunhão emprega argumentos que vão além daqueles éticos para ganhar relevância social em uma sociedade pluralista.

\begin{abstract}
“Esse Projeto é capaz de provar suas vantagens sociais e econômicas e de demonstrar que essas últimas são mais produtivas quando baseadas na cooperação entre os empregados e a administração. A sua base é mais sólida porque se sustenta na confiabilidade dos clientes, o que é oposto às práticas meramente contratuais. Além do mais, é capaz de diminuir os problemas sociais, o que é uma vantagem para toda a sociedade" (THIEMER, 1999, p. 103).
\end{abstract}

Com essa mesma missão, surgiu no Brasil o Pólo Empresarial Spartaco, localizado no estado de São Paulo, o qual foi construído especialmente para servir de "laboratório piloto" para abrigar as empresas que aderem a esse Projeto. Atualmente elas são seis: La Túnica (confecção), Rotogine (manufaturados de plástico), Eco-Ar (produtos de limpeza), Prodiet (distribuidora de produtos farmacêuticos), Uniben (fomento mercantil) e AVN (embalagens plásticas), as quais estão no mercado há 10 anos.

Passados 15 anos, desde a fundação desse Projeto no Brasil, as organizações que dele participam, já apresentam resultados positivos suficientes para uma avaliação desse novo e estranho estilo de gestão empresarial, especialmente na questão de lidar com as pessoas. Entretanto, quanto ao seu potencial para transformar a economia mundial, como é a intenção desse Projeto, ainda é muito cedo para uma avaliação desse tipo, como afirmam Gonçalves e Leitão (2001).

\title{
3 MÉTODO DA PESQUISA
}

\subsection{Objetivos e Terreno da Pesquisa}

O objetivo geral desta pesquisa consiste em analisar a qualidade de vida dos funcionários das empresas que aderem ao Projeto Economia de Comunhão (EdC), , especificamente aquelas do Pólo Empresarial Spartaco. Mais especificamente buscou- 
se analisar as relações interpessoais no tocante ao trabalho em grupo, a confiança, a solidariedade e a camaradagem entre os membros da organização; a organização do trabalho, em termos de constituição das tarefas, autonomia e participação dos membros; o estilo de direção, segundo os aspectos: proximidade entre superiores e subordinados, sistema de controle e comunicação; por fim verificar se os valores divulgados pelo Projeto Economia de Comunhão, em termos de relacionamento interpessoal, de organização do trabalho e de estilo de direção são aplicados pelas empresas estudadas, ou se ao contrário, ainda se encontram em adaptação.

Quanto ao terreno desta pesquisa, escolheu-se o Pólo Empresarial Spartaco, localizado em Cotia, interior de São Paulo, por ser considerado uma espécie de experiência piloto e um ponto de referência mundial para o Projeto EdC.

\subsection{Caracterização da Pesquisa}

Considerando-se as classificações e definições de diferentes tipos de pesquisas, este estudo tem um caráter exploratório e descritivo. Exploratório, pois se entende que apesar do tema qualidade de vida no trabalho já ter sido largamente estudado, o fenômeno Economia de Comunhão, ainda é desconhecido, não somente no meio acadêmico - poucas pesquisas na área de administração foram realizadas até agora, principalmente no tocante a gestão de pessoas - bem como no meio empresarial.

Seu caráter descritivo se deve ao levantamento de opiniões e de crenças acerca de alguns aspectos da qualidade de vida no trabalho, tanto da parte dos funcionários, quanto dos dirigentes.

Finalmente, pode-se caracterizar esta pesquisa como um estudo de caso, visto que tem como unidade de análise as organizações que compõem o Pólo Empresarial Spartaco.

\subsection{População e Amostra da Pesquisa}

A população desta pesquisa compreende os 17 dirigentes e os 61 funcionários das empresas que fazem parte do Pólo Empresarial Spartaco. Por considerar-se o tamanho do universo pequeno, decidiu-se não definir uma amostra.

Entretanto, apesar dessa decisão, apenas foi possível pesquisar 9 dirigentes e 43 funcionários, caracterizando-se pois, em uma população acessível, a qual corresponde a 52,94\% dos dirigentes e 70,49\% dos funcionários, respectivamente.

\subsection{Instrumentos de Coleta Dos Dados}

Os dados desta pesquisa foram colhidos através de observações diretas, entrevistas e questionário. A associação desses três métodos permite efetuar um trabalho de investigação em profundidade: supera-se uma carência dos métodos de pesquisa mais formais, como o questionário, o qual o rigor técnico que tem 
frequentemente por corolário uma falta de imaginação e de sensibilidade no plano das interpretações; compensa a superficialidade dos métodos de observação direta e de entrevista. Essa escolha permitiu proceder à coleta dos dados ao mesmo tempo qualitativa e quantitativa, utilizando instrumentos diferentes, mas complementares, indo do menos ao mais estruturado (SÁ, 1997).

Procedeu-se à observação de maneira a perceber se os funcionários do Pólo Empresarial Spartaco possuem qualidade de vida no trabalho em termos de Relacionamento Interpessoal, Organização do Trabalho e Estilo de Direção.

Através de entrevistas dirigidas, com perguntas precisas, pré-formuladas e em ordem preestabelecida pretendeu-se captar testemunhos e verdades, pois em geral,

\footnotetext{
“[...] permitem estudar os fatos dos quais a palavra é o vetor principal (estudo de ação passada, de conhecimento social, dos sistemas de valores e normas...) ou ainda, estudar o fato da palavra ela mesma (análise das estruturas discursivas, dos fenômenos de persuasão, argumentação, implicação)" (BLANCHET 1985 apud SÁ, 1997, p.152).
}

Quanto aos questionários, foram utilizados dois: um destinado aos diretores, outro aos funcionários. Eles foram baseados em dois construtos: o primeiro se refere aos fundamentos teóricos aqui utilizados; o segundo, diz respeito a uma adaptação do questionário construído por Sá (1997).

Enquanto os questionários foram compostos por questões fechadas (em uma escala do tipo Likert, dividida em seis casos: de "concordo totalmente" a "discordo totalmente") acerca dos fatores definidos para este estudo: relações interpessoais, organização do trabalho e estilo de direção, as entrevistas ajudaram a elucidar algumas questões, principalmente no intuito de revelar se os fatores da qualidade de vida do trabalho estudados já são adotados, ou se estes aspectos ainda se encontram em adaptação nas empresas que aderiram ao Projeto Economia de Comunhão, especificamente aquelas do Pólo Empresarial Spartaco.

\section{ANÁLISE DOS RESULTADOS}

\subsection{Aspectos das Relações Interpessoais}

O gráfico a seguir apresenta a percepção de dirigentes e funcionários em relação aos seguintes aspectos do relacionamento interpessoal: trabalho em grupo, confiança, solidariedade e camaradagem, nas empresas estudadas. 


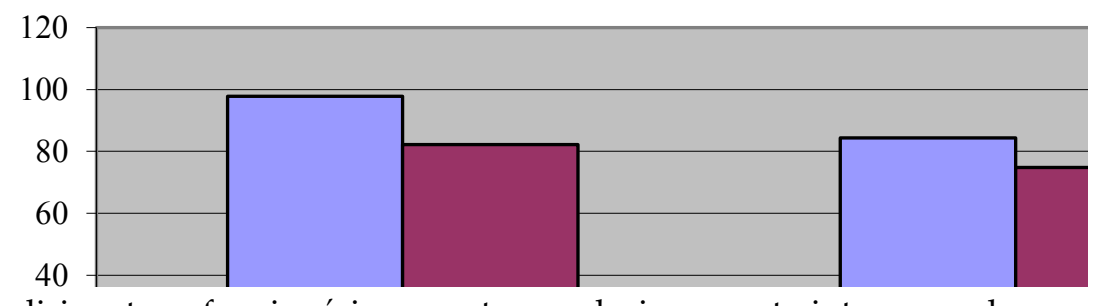

Gráfico 1: Opinião dos dirigentes e funcionários quanto ao relacionamento interpessoal Fonte: pesquisa das autoras

Trabalho em grupo: observando-se o Gráfico 1, percebe-se que tanto 8 dirigentes (97,8\%), quanto 35 funcionários $(82,2 \%)$, partilham da mesma opinião em relação ao trabalho em grupo nas empresas pesquisadas. Isso significa que as pessoas organizam-se entre colegas para realizar seus trabalhos, os funcionários colaboram com seus dirigentes e para eles a empresa representa uma extensão de suas casas. Ainda, tanto dirigentes quanto funcionários reconhecem a importância do relacionamento entre as pessoas para a realização das tarefas. Dessa forma, pode-se constatar o gosto pelo social nas relações dentro dessas organizações. Todavia, percebe-se uma ligeira discordância de opinião entre dirigentes e funcionários, no que concerne à questão relativa ao estímulo que a empresa oferece às relações interpessoais fora do ambiente de trabalho: enquanto todos os dirigentes afirmam positivamente, apenas 22 funcionários (um pouco mais do que a maioria: 51,2\%) confirmam isso.

Confiança: as opiniões da maioria dos dirigentes (8 ou 84,4\%) e dos funcionários (32 ou 74,8\%) relativas à confiança vão em um mesmo sentido. Isso evidencia que existe um bom nível de confiança entre os próprios funcionários e entre estes e seus dirigentes. E ainda, os dirigentes consideram os funcionários pessoas responsáveis e não preguiçosas. Nessas empresas o esforço que as pessoas fazem pela organização é reconhecido. Neste sentido, assim testemunhou um dirigente:

"Tem que haver um clima de confiança, pois os funcionários se abrem de acordo com a confiança que tem no empresário. É por causa da confiança que temos nos funcionários que fiscalizamos apenas os resultados".

Curioso observar, que a questão que mostrou maior discordância entre as opiniões de dirigentes e funcionários diz respeito à fiscalização cerrada: enquanto os dirigentes afirmam fiscalizar os funcionários durante a realização de seus trabalhos, apenas 21 desses últimos (48,8\%) confirmam essa questão. 
Solidariedade: observando o gráfico acima se pode inferir que existe mesmo solidariedade entre o pessoal: todos os dirigentes (9 ou 100\%) fazem essa afirmação e $35(82,3 \%)$ dos funcionários concordam. Dessa forma, pode-se concluir que nessas empresas os funcionários são solidários entre si para resolverem problemas de ordem pessoal. Mais ainda: os dirigentes os ajudam em seus problemas pessoais e se a empresa estiver com problemas pode contar com a ajuda deles, uma vez que os dirigentes também levam em conta o moral dos empregados. Eis o depoimento de um funcionário:

"Se tenho algum problema em casa eu deixo em casa. Mas se precisar de dinheiro os patrões ajudam, dinheiro ou qualquer outro problema. Se tiver problema pode ir lá, eles deixam as portas abertas".

Camaradagem: o Gráfico 1 mostra também que em todas as questões sobre camaradagem na empresa, há concordância entre os dirigentes (100\%) e os funcionários (36 ou 85,5\%). Assim, pode-se entender que nessas empresas existe amizade entre os funcionários, e certa informalidade no relacionamento entre superiores e subordinados. Nos grupos de trabalho as pessoas encorajam-se a trabalhar mutuamente, os colegas evitam fazer politicagem como forma de obter resultados, e mais: por gostarem de estar juntos, até se encontram fora do trabalho.

4.2 Aspectos da Organização do Trabalho

Gráfico 2: Opinião dos dirigentes e funcionários quanto a organização do trabalho Fonte: pesquisa das autoras

Tarefas: observa-se no Gráfico 2 que 82,3\% dos dirigentes e 70,2\% dos funcionários concordam que o trabalho realizado permite que os funcionários mudem de tarefa/posto, evitando assim a fadiga geralmente proveniente do trabalho repetitivo e monótono, como o que ocorre geralmente em ambientes industriais, que é o caso. Pode-se afirmar ainda que o trabalho realizado nessas organizações é parcelado. Porém, apesar do tipo de ambiente pesquisado (industrial) e de ambas as 
categorias pesquisadas concordarem que o trabalho realizado é parcelado, os funcionários não declaram o trabalho realizado como sendo aborrecido ou desinteressante. E mais, a maior diferença encontrada nas respostas de dirigentes e funcionários diz respeito à realização de um trabalho rotineiro e repetitivo. Enquanto a maioria dos dirigentes afirma que nas empresas pesquisadas o trabalho realizado é desse tipo, menos da metade dos funcionários concorda com isso. A respeito dessa opinião eis o depoimento de dois funcionários:

"Não considero o trabalho aborrecido ou desinteressante, ao contrário, trabalho alegre".

"O trabalho é bem interessante, pois nós aprendemos a mexer em todas as máquinas da empresa".

Autonomia: opiniões de dirigentes $(79,5 \%)$ e de funcionários $(73,9 \%)$ vão em um mesmo sentido, já que ambos concordam que os funcionários são encorajados a ter ações e idéias inovadoras. Os dirigentes afirmam ainda que os funcionários possuem autonomia para procurar novas maneiras de resolver os problemas e os funcionários compartilham dessa mesma opinião. Neste mesmo sentido, os funcionários afirmam que podem decidir sobre a maneira de executar as operações. A esse respeito afirmaram três funcionários:

"As idéias são muito importantes para eles".

"Os dirigentes nos perguntam se temos idéias"

"Aqui eles encorajam idéias novas e põe em prática"

A curiosidade encontrada a respeito da variável autonomia foi a de que a maioria dos dirigentes $(62,5 \%)$, afirma que os funcionários são punidos por seus erros, porém menos da metade dos funcionários, apenas $41,9 \%$, sentem que são punidos por eles. Assim, relatou um funcionário:

"Procura-se resolver os problemas juntos, sem punição".

Participação: a maioria das opiniões de dirigentes $(97,2 \%)$ e funcionários $(92,5 \%)$ levam a crer que nessas empresas se enfatizam as discussões em aberto e a tomada de decisão por consenso. Os dirigentes estão sempre dispostos a ouvir e a considerar as diferentes opiniões de seus funcionários, e ainda, os funcionários colaboram com os seus chefes e podem participar das decisões concernentes ao seu trabalho. Encontra-se o seguinte depoimento por parte de um dos dirigentes:

"Procura-se responsabilizar, conversar em grupo" 
Já com uma das funcionárias coletou-se o seguinte sobre a variável acima: "Uma vez por semana se fazem reuniões para ouvir os funcionários, mas, apenas com aqueles de escalões mais altos".

Alguns outros funcionários teceram comentários sobre a participação deles na empresa, opiniões estas que contrariam a análise quantitativa, especificamente, quando perguntados se os chefes estão dispostos a ouvir e a considerar as diferentes opiniões na empresa:

"Só hoje fiz três reclamações e nenhuma foi levada em consideração"

"Se o trabalhador tiver uma sugestão, pode falar e se for bom para a empresa, ela é acatada"

\subsection{Aspectos do Estilo de Direção}

Gráfico 3: Opinião dos dirigentes e funcionários quanto ao estilo de direção

Fonte: pesquisa das autoras

Controle: na opinião de dirigentes $(79,2 \%)$ e funcionários $(66,3)$ a disciplina não é considerada severa. A esse respeito os funcionários afirmam que:

"Eles não descontam nada, nem se chegar atrasado, nem se sair mais cedo, se tiver um problema em casa, pode sair".

"Se houver justificativa para faltas e atrasos, eles não são rígidos".

Ainda sobre o controle encontrou-se na análise quantitativa que a autoridade é exercida com benevolência. E ainda, o trabalho nessas organizações é executado segundo métodos formais e procedimentos. Curiosamente, osdirigentes, alguns deles, assumem que as pessoas são fiscalizadas durante o seu trabalho, opinião que também é compartilhada por dos funcionários. Sobre este aspecto dois dirigentes enfatizam: 
"As pessoas sabem o que tem para fazer, não precisam de fiscalização direta".

"Ao invés de fiscalizar eu diria que acompanhamos os funcionários"

Comunicação: de acordo com a opinião de funcionários $(89,6 \%)$ e dirigentes $(94,5 \%)$ referente à comunicação, pode-se inferir que, existe acesso às informações para o desenvolvimento do trabalho e existe liberdade para se expressar. Ainda sobre a comunicação na empresa, verificou-se existir comunicação informal entre os membros das empresas e ainda foi revelado que os funcionários sabem quais são os principais objetivos, metas ou planos da empresa, porém dois funcionários fizeram as seguintes declarações a esse respeito:

"O objetivo da empresa é melhorar sempre mais".

"O objetivo da empresa é em primeiro lugar, expandir, em segundo lugar, a comunhão de bens".

Proximidade: Para funcionários (82,2\%) e dirigentes (91,7\%), nas organizações pesquisadas as pessoas são ajudadas nos seus problemas pessoais. Parece também existir contato direto entre os dirigentes e os funcionários. Os funcionários ainda afirmam que para eles a empresa representa uma extensão de sua casa e essa opinião é compartilhada pelos dirigentes. Da mesma forma funcionários e dirigentes afirmam não existir sentimento de superioridade e de inferioridade nas relações interpessoais. Eis aí o depoimento de dois dirigentes:

"Quando se percebe que alguém está mal, procura-se chegar no funcionário, ficamos bem atentos a isso".

"Se há a percepção de que as pessoas querem ser ajudadas nós estamos prontos a isso". O mesmo ainda complementa: "A vida não é dividida em departamentos, se ele está feliz em casa, está feliz também no trabalho".

Já os funcionários declararam:

"Não deixam de nos ajudar quando precisamos".

\subsection{Análise das Observações Diretas}

Observou-se, que nas empresas pesquisadas, existe proximidade entre superiores e subordinados, uma vez que, alguns dirigentes fizeram questão de apresentar a fábrica e ainda de apresentar os seus funcionários, chamando a cada um pelo nome. Inclusive em uma das empresas pode-se presenciar a volta de uma gerente das férias e o carinho com que trata os funcionários, trazendo-lhes inclusive souvenirs e ainda a empolgação e alegria dos funcionários pelo retorno da mesma. 
Algumas empresas pesquisadas possuem departamentos inteiros compostos apenas de uma pessoa, encontrando-se até uma empresa com apenas um funcionário, onde isso ocorre verificou-se essas pessoas 'estressadas' e com ar de cansaço, provavelmente pela sobrecarga de trabalho e responsabilidade que carregam.

\section{CONSIDERAÇÕES FINAIS}

Conforme Vergara e Branco (2001, p. 20), são ingredientes importantes das organizações de sucesso, ou melhor, das "empresas humanizadas": o trabalho em grupo, a confiança, a camaradagem e a solidariedade. Deste modo, no que diz respeito às relações interpessoais, a pesquisa indica que as empresas pesquisadas são mais humanizadas, apontando que as atividades são desenvolvidas muito mais em grupos do que individualmente e ainda apresentando a existência de um clima de maior camaradagem, solidariedade e confiança entre seus integrantes.

Em relação à organização do trabalho, no que diz respeito às tarefas, embora estas não sejam programadas de forma a valorizar mais a competência e a autorealização de seus participantes, mesmo assim, os funcionários trabalham satisfeitos, e não as consideram aborrecidas e desinteressantes, até mesmo porque o modo de realização dessas tarefas permite um maior nível de autonomia de seus executores. Por fim, constatou-se que os empregados participam nas decisões da empresa, pelo menos aquelas que lhes concernem. Também Grandjean (1998) afirma que vários levantamentos realizados mostraram que uma parte importante dos trabalhadores pesquisados acha sua tarefa repetitiva, mas, curiosamente a acham interessante e que frequentemente só uma metade acha seu trabalho monótono. Dessa forma, Grandjean, (1998, p.153) ainda afirma que: "nem a prática empresarial nem pesquisas científicas conseguiram ainda, até hoje, encontrar um efeito uniforme do trabalho monótono e repetitivo sobre as pessoas, em relação à satisfação com o trabalho".

Em relação ao estilo de direção, pode-se afirmar que existe aproximação e confiança entre os dirigentes e os empregados e ainda, que o sistema de controle é mais indireto, o que normalmente não acontece em empresas comuns. Finalmente, quanto à comunicação entre os membros, pode-se afirmar que ela se dá sem formalismo, valorizando a troca de idéias e de informações. Neste sentido, Cohen (1999) destaque que a nova exigência para as organizações que querem continuar no mercado, é que as mesmas se tornem organizações holísticas, se preocupem menos com o controle dos processos e encoraje mais o relacionamento entre líderes e liderados, entre os colegas, entre as unidades das organizações. Mais: ela deve ser consciente do contexto maior: o humano, corporativo, social e ecológico- e deve aumentar suas relações com ele (COHEN, 1999).

Apesar da análise quantitativa dos dados indicar que os fatores estudados, relações interpessoais, organização do trabalho e estilo de direção apontarem para empresas que oferecem qualidade de vida aos seus funcionários, as análises 
qualitativas revelam alguns sinais contrários, os quais merecem maior atenção em futuros trabalhos de pesquisa.

Quanto aos valores divulgados por esse Projeto, em termos de qualidade de vida no trabalho, são em sua maioria aplicados pelas empresas estudadas, encontrando-se alguns ainda em adaptação.

Como limitação para este estudo, é bom destacar a dificuldade de se encontrar pesquisas relacionadas à gestão de pessoas em empresas que aderem ao Projeto EdC e ainda a necessidade de se dar uma maior ênfase na coleta de dados qualitativos, devido principalmente a algumas divergências que foram encontradas entre a análise quantitativa e a qualitativa. Recomendando-se para trabalhos futuros uma maior utilização desse último tipo de análise, procurando-se desta forma esclarecer qualquer dúvida que possa surgir em uma pesquisa que tenha como maior peso à análise quantitativa; depois, que seja feito um estudo para analisar até que ponto os valores espirituais dos dirigentes dessas empresas interferem no relacionamento interpessoal, na organização do trabalho e no estilo de liderança adotados.

Necessário se faz salientar, que não é pretensão das pesquisadoras serem conclusivas neste estudo, mas acreditamos que com ele, criou-se à possibilidade de novos campos de pesquisa dentro dessa abordagem, a partir das idéias aqui lançadas.

\section{REFERÊNCIAS}

AGUIAR, Maria de Fátima. Lazer e produtividade no trabalho. In: Reunião Anual ANPAD, 24, 2000, Florianópolis. Anais...Florianópolis, ANPAD, 2000.

BARDIN, Laurence. Análise de Conteúdo. Tradução Luís Antero Reto e Augusto Pinheiro. Lisboa: Edições 70, 1977.

BOM SUCESSO, Edina de Paula. Trabalho e qualidade de vida. Rio de Janeiro: Qualitymark/ Dunya, 1997.

CAIXETA, Nely. A verdadeira Virada de Mesa. Revista exame, São Paulo: Editora Abril, p. 40-50, 22 ago. 2001.

COHEN, David. Mas esta agora: Será que eu tenho de saber Física Quântica? Revista Exame, São Paulo: Editora Abril, ano 33, n 23. p. 106-112,14 nov. 1999.

CURADO, I. B. et al. Mitos e Realidades da Gestão de Recursos Humanos. Revista de Administração de Empresas Light. São Paulo, ano 2, n 6, p. 6-8, 1995.

DEJOURS, Christophe. A loucura do trabalho: estudo de psicopatologia do trabalho. São Paulo: Cortez - Oboré, 1992. 
FERNANDES, E. da C. Qualidade de Vida no Trabalho: como medir para melhorar. Salvador: Casa da Qualidade, 1996.128p.

FERRUCCI, Alberto. Uma dimensão diferente da economia: a experiência Economia de Comunhão. In: Economia de Comunhão: Uma cultura econômica de várias dimensões. São Paulo: Cidade nova, 2002. p. 31-40.

FRIEDMAN, Stewart D.; CHRISTENSEN, Perry; DEGROOT, Jessica. Trabalho e Vida pessoal: o fim do jogo soma zero. Trabalho e vida pessoal. tradução Loreley Mello Baptista de Sá Freire. Rio de Janeiro: Editora Campus, 2001. 212p.

GOMES, Maria Tereza. Entenda as estrelas do guia. Guia Exame: As melhores empresas para você trabalhar:, p. 48-49, 1999. Edição Especial. Parte integrante da edição 695.

GUI, Benedetto. Organizações produtivas com finalidades ideais e realização da pessoa: relações interpessoais e horizontes de sentido In: Luigino Bruni (Org.). Economia de Comunhão: Uma cultura econômica de várias dimensões. São Paulo: Cidade nova, 2002. p. 111-127.

GARCIA, Adriane. Você não vai mais ter secretária. Revista Exame, São Paulo: Editora Abril, ano 32 n.6.ed 684, p. 110-112. 24 mar. 1999.

GONÇALVES, Heloisa H. A. Borges; LEITÃO, Sérgio Proença. Empresas da economia de comunhão: o caso Femaq. RAP-Revista de Administração Brasileira, Rio de Janeiro, v 35, n 6, p.33-59. Nov/ dez. 2001.

GRANDJEAN, Etienne. Manual de ergonomia: adaptando o trabalho ao homem. 4. ed. Porto Alegre: Bookman, 1998. 338p.

LUBICH, Chiara. O movimento dos Focolares e a Economia de Comunhão. In: Economia de Comunhão e Movimento Econômico: desenvolvimento e perspectivas, 1,1999, Vargem Grande Paulista- SP. Anais... Vargem Grande Paulista: Bureau internacional da economia e trabalho, 1999. P.9-19

. O Movimento dos Focolares e a Economia de Comunhão.ABBA: Revista de Cultura, São Paulo, vol. IV, n. 3, p. 9-18. Cidade Nova, 2001.

A experiência Economia de Comunhão: da espiritualidade da unidade, uma proposta de agir econômico In: Economia de Comunhão: Uma cultura econômica de várias dimensões. São Paulo: Cidade nova, 2002. p. 13-19 
MACHADO, Mariângela Moreira. Qualidade de vida no trabalho: Uma variável a ser considerada dentro dos programas de qualidade total. 1996 174f. Dissertação (Mestrado em Administração)- Universidade Federal da Paraíba, João Pessoa, 1996.

MARCHI, Ricardo de. Qualidade e Produtividade. RH em Síntese, São Paulo, n.32. jan/fev. 2000.

MORIN, Estelle M. Os Sentidos do Trabalho. Revista de Administração de Empresas, São Paulo,.v 41, n 3, p.8-19, Jul. /set. 2001.

OLIVARES, Inês Cozzo. O novo profissional de T e D. Revista Treinamento e Desenvolvimento, São Paulo, v.2, n 17, p.37-38, maio 1994.

PICCININI, Valmiria Carolina; OLIVEIRA, Sidnei Rocha. Flexibilização, Qualidade de vida e Empregabilidade: o caso das cooperativas de trabalho de Porto Alegre. In: Reunião Anual ANPAD, 26, 2002, Salvador. Anais...Salvador: ANPAD, 2002.

POLIGNANO, Fernando. A comunicação como instrumento para uma melhor qualidade de vida nas empresas. Revista Treinamento e Desenvolvimento, São Paulo, p. 30-31, ago. 1995.

SÁ, Maria Auxiliadora Diniz de. Facteurs culturels et organisationnels de l'implication dans l'entreprise. 1997. Tese (Doutorado em Administração) Rouen, Université de Rouen, 1997.

SÁ, Maria Auxiliadora Diniz de; LEMOINE, Claude. O estilo de liderança como fator de comprometimento nas empresas. In: Reunião Anual ANPAD, 22, 1998, Foz do Iguaçu. Anais... Foz do Iguaçu: ANPAD, 1998.

SÁ, Maria Auxiliadora Diniz de; LEMOINE, Claude. Em matéria de comprometimento na empresa são os valores individuais que contam. In: Reunião Anual ANPAD, 23, 1999 Foz do Iguaçu. Anais... Foz do Iguaçu: ANPAD, 1999.

SANT'ANNA, Anderson de Souza; et al. Qualidade de vida no trabalho: uma análise em unidades de ensino básico. In: Reunião Anual ANPAD, 24, 2000, Florianópolis. Anais...Florianópolis, ANPAD, 2000.

SEMLER, Ricardo Frank. Virando a própria mesa: uma história de sucesso empresarial made in Brazil. São Paulo: Best Seller, 1988. 274p. 
SCHUTZ, W.C. Firo: A three dimensional theory of interpersonal behavior. New York: Reinhart, 1958.

SILVA, Lisiane Vasconcelos da; ANTUNES, Elaine Di Diego. Influência das relações flexíveis de trabalho na qualidade de vida do trabalhador: a visão de seus atores sociais. In: Reunião Anual ANPAD, 26, 2002, Salvador. Anais... Salvador, ANPAD, 2002.

SILVA, Dias. Qualidade de Vida.In: $1^{\circ}$ Workshop Serasa de Qualidade de Vida. Disponível em <www.gestaoerh.com.br/artigos/saud 005.shtml>. Acesso em: jul. 2000.

THIMER, Stefan. Economia de Comunhão: um modelo para a sociedade. In: Economia de Comunhão e Movimento Econômico: desenvolvimento e perspectivas, 1,1999, Vargem Grande Paulista- SP. Anais... Vargem Grande Paulista: Bureau internacional da economia e trabalho, 1999. p.100-107.

VERGARA, Sylvia Constant; BRANCO, Paulo Durval. Empresa Humanizada: a organização necessária e possível. RAE - Revista de administração de empresas.. São Paulo. n. 2 p.20-30, abr./ jun. 2001.

VIEIRA, Adriane. A qualidade de vida no trabalho na gestão da Qualidade Total. In: Reunião Anual ANPAD, 20, 1996, Angra dos Reis. Anais... Angra dos Reis, ANPAD, 1996. p. 353-373. 